\title{
MIXING PLEASURE AND BEAUTY: POSITIVE AESTHETIC EXPERIENCE IN OLD ENGLISH POETRY
}

\author{
Francisco Javier Minaya Gómez \\ Universidad de Castilla La Mancha \\ francisco.minaya@uclm.es
}

\begin{abstract}
This article analyses 23 different lexical items in Old English denoting positive aesthetic emotion, more specifically, related to the expression of appearance, moral qualities, and personal pleasant experience with the aim of gaining a better understanding of aesthetic standards in Anglo-Saxon England. Using different lexical tools, corpora and software, I have built a database where I have annotated the attestations from the corpus taking into account different sociolinguistic criteria. An in-depth analysis of these fragments and their statistical treatment has shown that descriptions of beauty in Old English poetry have two main routes: a) one that addresses the object's aesthetic qualities objectively and b) another that focuses on the subject's response to it. Furthermore, these two alternatives were often complementary in texts of a religious nature.
\end{abstract}

Keywords: Old English poetry, Old English beauty, aesthetics, historical linguistics, cognitive linguistics, history of emotions, aesthetic emotions. 


\title{
MEZCLANDO LA BELLEZA Y EL PLACER: EXPERIENCIA ESTÉTICA POSITIVA EN LA POESíA EN INGLÉS ANTIGUO
}

\begin{abstract}
RESUMEN. Este artículo analiza 23 lexemas que denotan emociones estéticas positivas en inglés antiguo, más en concreto, relacionados con la expresión de la apariencia, la moralidad y la experiencia personal agradable, con el objetivo de entender mejor la experiencia estética en la Inglaterra anglosajona. Valiéndome de distintas herramientas lexicográficas, corpus textuales y software informático, he creado una base de datos donde he anotado las atestaciones del corpus atendiendo a distintos criterios sociolingüisticos. Un análisis en profundidad de estos fragmentos y su tratamiento estadístico ha demostrado que las descripciones de belleza en la poesía en inglés antiguo tienen dos rutas principales: a) una que se centra en las cualidades objetivas del objeto y b) otra se limita a la respuesta del sujeto. Estas dos posibilidades a menudo son complementarias en textos de una naturaleza religiosa.
\end{abstract}

Palabras clave: poesía anglosajona, belleza anglosajona, estética, lingüística histórica, lingüística cognitiva, historia de las emociones, emociones estéticas.

Received 11 November 2019

Revised version accepted 16 June 2020

\section{INTRODUCTION ${ }^{1}$}

Descriptions of superb beauty and aesthetic pleasure populate Old English poetry. These are usually quite lengthy passages where the aesthetic objects are described with a great variety of aesthetic emotion lexis. However, very limited research has been done on how these terms are used and what type of aesthetic judgment they carry out.

The present article aims at answering questions related to the nature of the aesthetic emotion episode in Old English poetic texts, chiefly how passages depicting aesthetic emotion combine lexis relating to the aesthetic object's objective qualities and the subjective feelings experienced by the subject. Secondary aims of this paper include answering questions as to how the nature of the stimuli depicted in the poetic fragments affects the emotion episode, and what type of stimuli is more frequent in these texts, either cognitive or sensory.

In order to do so, I will look into two of the principal thematic groups, that is, lexical domains, in positive aesthetic emotion vocabulary. Drawing on corpus linguistics methods (e.g. Gries 2010; Gries and Otani 2010), aesthetic emotion

1 The research reported here has been supported by the research project SBPLY/17/180501/000267 and by a pre-doctoral contract funded by the University of Castilla-La Mancha and the ESF (European Social Fund). 
theories (e.g. Juslin 2013; Menninghaus et al. 2019) and different lexical toolsincluding thesauri of Old English-, I have analysed the usage of a number of lexical items and their context-the poem in which they occur-, and cotextadjacent lexis - , to gain a better understanding of the aesthetic criteria implicit in these descriptions of beauty and pleasure. Thereafter, I have highlighted the most illustrative examples of usage of these lexical items in order to support the findings of the data-driven remarks derived from the analysis of the complete poetic corpus.

\section{BEAUTY, AESTHETIC PLEASURE AND AESTHETIC EMOTIONS}

Over the last few years, the study of Old English texts from a cognitive perspective has adopted new perspectives that yield new readings into the cultural and emotional models of the Anglo-Saxons. For instance, Gevaert's (2007) diachronic analysis of ANGER in Old English following metaphor theories, Lockett's (2011) volume on Anglo-Saxon psychology and figurative expressions or Díaz-Vera's (2015) exploration of the Anglo-Saxon emotion of AWE stand out as perfectly illustrative examples of how cognitive linguistic research can provide insights that traditional literary analysis cannot. However, the field of Anglo-Saxon aesthetics is yet to fully embrace the cognitive approach, as most publications on Old English beauty do not take into consideration the ground-breaking research being carried out on the experience of beauty as a fundamentally embodied phenomenon, which leaves aside the idea of beauty as a philosophical and theological reality.

The study of aesthetic emotions has bloomed during the last two decades. The development of emotion theories at the end of the last century (Izard 1977; Scherer 1982; Frijda 1988; Lazarus 1991; Damasio 1999; or Roseman et al. 2001) allowed for more exhaustive research into aesthetic experience and how humans feel pleasure and beauty when experiencing artworks and other everyday objects. Since Berlyne's (1974) foundational treatises on experimental aesthetics, many researchers have put forth their theories on aesthetic emotions, focusing more frequently on positive reactions to aesthetic objects. Therefore, there is an abundance of academic material on positive aesthetic experience, that is, all the different aesthetic emotions that range from the sheer pleasure of beholding a pleasant aesthetic object, to the experience of beauty and wonder.

Among these works, there are some with particular relevance to this study that can potentially contribute to the present analysis of beauty and pleasure in AngloSaxon poetry. One of the most fertile branches in the study of aesthetic emotions is what Munteanu (2009: 117) calls the "reception of art". This branch "focus[es] on the manner in which audiences, more specifically viewers and readers, experience 
emotion" (Munteanu 2009: 118). There are researchers like Munteanu (2009), Shibles (1995) or Hagman (2005) who frame aesthetic experience within an exclusively artistic context, while others like Scherer (2005), Menninghaus et al. (2019) or Marković (2012) acknowledge that aesthetic experience is also extensive to everyday objects.

Scherer (2005), who highlights the nature of aesthetic emotions as being a non-utilitarian one, defines aesthetic emotions as follows:

aesthetic emotions are produced by the appreciation of the intrinsic qualities of the beauty of nature, or the qualities of a work of art or an artistic performance. Examples of such aesthetic emotions are being moved or awed, being full of wonder, admiration, bliss, ecstasy, fascination, harmony, rapture, solemnity (Scherer 2005: 705).

It is, therefore, reductive to limit aesthetic experience to only the experience of beauty. In this regard, when carrying out research on aesthetic emotions, the notions of what qualifies as aesthetic experience must be broadened to encompass a wider lexical domain. Nevertheless, what is clear from Scherer's (2005) paper is that aesthetic emotions are seen as emotions which lack utility and are not action-oriented.

Following on theories of appraisals proposed by Frijda et al. (1989) and later by Roseman and Smith (2001), Scherer (2005) and Menninghaus et al. (2019) propose some appraisals for aesthetic emotion. Scherer (2005: 703) proposes the appraisal of intrinsic pleasantness as central to aesthetic experience, while Menninghaus et al. (2019: 28) produce a more extensive list that includes appraisals of novelty, familiarity, goal relevance, goal conduciveness and coping potential. The study carried out by Menninghaus et al. (2019) stresses an important connection between the familiarity and the novelty in an aesthetic object: it will be perceived as appealing if it is novel and also if it is familiar. Although this may pose a contradiction, it is, in fact, in the combination of these appraisals where the full potential of aesthetic experience develops: when an aesthetic object is presented as novel in some way in a familiar context, the perceived "intrinsic pleasantness," following the terminology used by Scherer (2005), will be remarkably strong. In fact, it has been shown how in some OE texts the novel is precisely appreciated because it is anchored in the familiar. As Bitterli (2016: 160) and Kim and Mittman (2010: 687) explain as regards OE texts, most of the patterns of novelty or strangeness are not so radical as to severe all connection with the idea of the familiar, but they are rooted in the formulaic (and, hence, familiar) and anthropomorphic patterns that contribute to a more intense and/or easily accessible aesthetic experience. 
As for the aesthetic emotion episode, many models have been proposed over the last years. Especially interesting are those put forth by Markovic (2012) and Juslin (2013). Both these models acknowledge the separate action of the sensory and the cognitive evaluation of the aesthetic object in order to produce an aesthetic judgment, which, following Cupchick (2016: 12), will result in an aesthetic emotion if this judgment is above the subject's aesthetic threshold and, therefore, salient. If not, the subject will still experience changes in his emotional state as a result of their interaction with the aesthetic object. Therefore, three levels of action should be highlighted within positive aesthetic experience: the sensory, the cognitive and the emotional, with their pertinent subdivisions. The sensory unfolds in the different senses involved in the aesthetic emotion episode (chiefly, sight, smell and hearing). The cognitive involves different ideas like morality, spirituality and social considerations. The emotional dimension of aesthetic emotions entails the affection felt towards a given aesthetic object, as well as the subject's emotional background.

Another concept that is emphasised in most theories of aesthetic emotions is the importance of expression. It was already noted in the $19^{\text {th }}$ century by Bosanquet (1894: 155): "the expression of beauty reduces itself to expressiveness". Scherer (2005: 707) enumerates a list of ways in which the subject may express this (aesthetic) emotion. Since aesthetic emotions are less action oriented, as stated by Scherer (2005: 12), the fundamental data source for research into the historical expression of aesthetic emotions has to necessarily rely on the linguistic expression of this emotion. In the aesthetic emotion episode, as proposed by Juslin (2013: 248) the sensory, emotional and cognitive information is filtered by the subject's aesthetic criteria, which are heavily influenced by the culture in which the subject lives or is raised in. This idea reflects Ibarretxe-Antuñano's (2013: 324) metaphor of 'culture sieve': in the emotion episode, culture acts as a sieve that permeates it with cultural meanings. This implies that by analysing a given linguistic utterance which represents the expression of an aesthetic emotion, aesthetic criteria and, therefore, the cultural models of aesthetic experience can be reconstructed within certain limits.

There are no works in the literature that address aesthetic experience in $\mathrm{OE}$ texts as such. While there exist many volumes written on the Western canon of beauty, and there are few publications on Old English beauty, there is not a consistent or exhaustive line of research for aesthetic emotions in the Anglo-Saxon period, not even one limited to the experience of beauty. These publications include an article by Ramey (2017) on one of the lexical descriptors of beauty, OE wrātlic 'wondrously beautiful', a book on the aesthetics of Beowulf and other Anglo-Saxon poems edited by Hill (2010), an article by Trilling (2009) describing the aesthetics of nostalgia, and the work by Tyler (2006), who produced a volume 
on the aesthetics of the familiar. Most of these works, however, address beauty from a literary perspective, and while this methodology is perfectly valid, the inclusion of linguistic methods can benefit the study of Anglo-Saxon beauty.

Likewise, the literary and artistic approach of the myriad treatises on (Medieval) beauty can provide data that can inform the linguistic analysis of the data in the concordance. Of special importance to the data in this study are the ideas discussed in Umberto Eco's (2004) On Beauty: A History of a Western Ideal, and Arthur Marwick's (2004) It: A History of Human Beauty. In the initial section, Eco (2004) sets the bases of how Medieval beauty was construed, whereas Marwick (2004) focuses on how important or otherwise beauty was at a personal level.

Eco (2004) points out some of the ideas that are applicable and central to beauty as represented in OE poetry. First, he emphasises the connection between moral beauty and physical beauty, already discussed by Minaya (2019) in the context of Old English texts. In this sense, for a person to be beautiful in Medieval time (and in the Anglo-Saxon period) they had to be perceived as morally beautiful or clean. Secondly, he reinforces the idea of light as connected to the beauty of the divinity and reflected in the beauty of human beings as a result of their spiritual purity. Thirdly, Eco (2004) applies this idea of light to ornaments: they are valuable not only because they are made of precious materials, but because they reflect light. Finally, Eco (2004) points out how, contrary to popular belief, the usage of colour in Medieval times was a usual practice for higher classes, in manuscript decoration, and in adorning churches, as well as in poetic texts.

However, Marwick (2004) deems this experience of beauty as elitist, and goes on to explain how trivial was beauty in everyday life for Medieval common people. Marwick (2004: 25) points out that "personal appearance was scarcely a matter of great concern". Moreover, the priority of common people was "rearing of (comparatively) healthy children for continuance of the family and [...] support when earning powers failed. The imperatives, then, were far other than those of sexual aesthetics" (Marwick 2004: 25). These remarks have several implications in light of the study of aesthetic emotions in OE. First, due to the nature of the historical research, and because everyday aesthetic experience is not documented in the sources, it is not possible to have access to first-hand accounts on aesthetic experience. Second, that most of the written material with aesthetic content will belong to a higher stratum of society: those who could write and had access to beautiful objects, mainly the clergy. Third, that, despite any resilient native AngloSaxon substratum, these considerations on beauty will inevitably be influenced by centuries of Christian tradition and religious aesthetic imperatives. For this, the present study focuses exclusively on poetic texts: not only will they be more accurate in representing the native Anglo-Saxon aesthetic model (with due 
limitations), but they will also serve to show how the Anglo-Saxon scribe or poet, using the analysed lexical items, aims at engaging the subject in a full-blown aesthetic experience.

\section{METHODOLOGY}

\subsection{DATA}

As I have mentioned before, it is now nearly impossible to aim at a reconstruction of the Anglo-Saxon everyday aesthetic experience. The absence of living informants and the formal characteristics of the extant visual and written material notably limit the scope of the research carried out here. Therefore, the objectives of this partial reconstruction of the Anglo-Saxon cultural model for positive aesthetic emotions are limited to the intentional creation of beauty on the part of poets and translators.

There are several corpora available to conduct linguistic research on Old English. One of the most frequently used corpora is The Diachronic Part of Helsinki Corpus of English Texts, whose section on Old English contains 415,000 Old English words. This corpus is designed to contain a balanced number of texts in terms of genre and periods. The Helsinki Corpus contains two main offshoots: the York-Toronto-Helsinki Parsed Corpus of Old English Poetry (with 71,490 words) and the York-Toronto Helsinki Parsed Corpus of Old English Prose (circa 1.5 million words). Lastly, there is the Dictionary of Old English Corpus (henceforth, DOEC), with a grand total of 3 million Old English words. This corpus is a record of every extant Old English text and sometimes two or more copies are included if they are interesting to look at in terms of period or dialect. More specifically, the verse section of the DOEC contains around 177,000 OE words.

Two of these corpora would have suited the purposes of this study. The YorkToronto-Helsinki Parsed Corpus of Old English Poetry was one of the choices, since it contains the relevant part of the Helsinki Corpus. However, when compared in terms of words to the DOEC $(71,490$ against 177,480$)$, it is clear that DOEC is the better choice. As Möhlig-Falke points out:

the DOEC may be the better choice for linguistic investigations that are interested in, for instance, lexical, semantic, pragmatic and discourse phenomena of Old English, for which it is often necessary to take a closer look at the cotext and the context of a specific utterance or for which the full text needs to be considered (2016: 397)

Since the analysis of the lexical items in this study is not only carried out in linguistic terms, but also taking into consideration the contextual and cotextual information of the occurrence, in this regard the DOEC is also the best choice. 
Moreover, given the fact that the York-Toronto-Helsinki Corpus of Old English Poetry is parsed, the continuous reading of selected fragments of poems under analysis becomes more time-consuming.

In this sense, this piece of research is not strictly corpus based, but rather data driven, as the $D O E C$ is a faithful representation of the known poetic material. It was compiled in the 1970s, and finally released in 1981. It was last updated in 2009. Concerning the poetry section, most of the texts contained therein are written in the West-Saxon dialect and, following the sub-periods of the larger OE period proposed by the Helsinki Corpus (see Kytö 1996), written down between 950 and 1150 (OE III and OE IV) in four main manuscripts: the Junius Manuscript, the Exeter Book, the Vercelli Book and the Beowulf Manuscript. Nevertheless, the oral nature of poetry in Anglo-Saxon and the archaisms present in the poems indicate that these poems might have been in circulation since many centuries before they were attested in writing.

\subsection{CHOICE OF LEXICAL ITEMS}

The selection of lexical items for this research was guided by the Thesaurus of Old English (henceforth, TOE). In this thesaurus, OE vocabulary is divided by different themes and subthemes. Section 7, which concerns "Opinion," more specifically "Judgment, forming of opinion" (TOE, n7) contains a subdivision devoted to "Beauty, fairness" (TOE, n7, 10) and yet another subdivision more particular to "Elegance, beauty, comeliness" (TOE, n7, 10, 2). For other positive emotions, like pleasure, the subdivision "Pleasantness, agreeableness" (TOE, n8, 1, 1, 3, 9), within the category of "Emotion" (TOE, n8) was used.

The TOE provided an initial list of 41 lexical items denoting positive aesthetic emotions. This list was then complemented and contrasted by the definitions in two OE dictionaries, the Dictionary of Old English (henceforth, DOE) and the Bosworth-Toller Anglo-Saxon Dictionary (henceforth, BTD). This provided a list of 69 words. The inclusion of some additional lexis will be discussed in section 4 in the relevant thematic group. This lexis was sorted out in the following thematic groups, which are modified from the categories proposed by the TOE: a) adornment, b) appearance, c) cleanness, d) colour, e) excellence, f) intricacy, g) light and h) pleasure. Due to space limitations, this article focuses exclusively on aesthetic experience as related to appearance and pleasure. Far from being an arbitrary choice, contrasting these two groups further illustrates the nature of the Anglo-Saxon aesthetic emotion episode from its two perspectives: the subject's experience and feelings of pleasure when facing the aesthetic object, and the object's perceived aesthetic qualities. 
MIXING PLEASURE AND BEAUTY: POSITIVE AESTHETIC EXPERIENCE IN OLD ENGLISH POETRY

\subsection{METHODS OF DATA COLLECTION, CATEGORISATION, TREATMENT AND ANALYSIS}

This study combines methods from different disciplines, from corpus linguistics to cognitive sociolinguistics or ethnopragmatics. The corpus mentioned before, the DOEC, was loaded onto a concordance software, where the instances of the different spelling varieties of the lexis mentioned in the preceding section were systematically annotated according to their thematic group and standardised spelling. However, this was not enough to carry out an in-depth analysis of the lexis in the poetic texts. Aided by the tags in the texts and by the relevant translations of the OE texts-chiefly Williamson's (2017) translation of the complete poetic corpus-, the occurrences were imported onto a database after a continuous reading that could provide full contextual and lexical information for its categorisation.

In this sense, this methodology draws upon lexical semantics, in other words, the "study of lexical items, their distribution, and what their distribution reveals about their semantics and pragmatics / discourse function(s)" (Gries and Otani, 2010: 121). Traditional lexical semantics aims at broadly considering some of the linguistic context in which the occurrence appears. Similarly, this approach allows for a thorough analysis of the word in question which ultimately can provide information as to its cultural and cognitive associations in a language. In this case, the aim is identifying the encoded aesthetic judgment in the selected terms and their lexical companions. However, this methodology as described by Miller and Charles (1991) and the usual methods of corpus linguistics have the main drawback that the occurrence is often isolated in the larger cotextual context. The Behavioural Profiles (BP) methodology, which was designed by Gries (2010), Gries and Otani (2010) and Gries and Divjak (2009) aims at overcoming some these limitations. It implements the usage of a database where substantial fragments containing the lexical items are imported onto a database, in which they are manually annotated and are treated statistically.

Gries (2010: 327-9) methodology proposes the following steps: a) retrieving "(a representative random sample of) all instances of the lemmas of the word(s) to be studied form a corpus in the form of a concordance," b) creating a concordance with "(so far largely) manual analysis and annotations of many properties $^{2}$ of each match in the concordance of the lemmas," c) to convert "these data into a co-occurrence table that provides the relative frequency of co-occurrence of each lemma/sense with each ID tag," and, finally, d) to evaluate "the co-occurrence data [...] by means of statistical techniques". This

2 For specific properties, Atkins (1987) points out a list of identification tags that distribute lexical items according to morphological, syntactic and semantic criteria. 
methodology was followed with marked exceptions for the categorisation of the instances in the corpus.

After the initial systematic annotation of the occurrences in the corpus, I manually introduced the fragments containing the attestation into the database. These fragments contained at least one full sentence, two if it was the case of an omitted subject. If the passage was particularly interesting in aesthetic terms, larger fragments were imported. Afterwards, these passages were analysed, translated and categorised on the basis of the following criteria:

a) the emotion represented, whether it was the experience of beauty or pleasure;

b) the standardised spelling of the term in the fragment;

c) the thematic group it belongs to;

d) the nouns, adjectives, adverbs and/or verbs that collocate with the analysed lexical item;

e) text name and citation; and

f) the three main categories designed for this study, designed as follows. The fragments were tagged in three different blocks depending on the evaluation that took place. As mentioned in Section 1, aesthetic judgment operates on two fundamental domains: the sensory and the cognitive. However, these are extremely broad categories. For the purposes of this study, I created specific tags for each of these domains of action:

1. The sensory: depending on the sensory treatment that the aesthetic object received, the occurrences were categorised in one of the following subcategories: 1) sight, 2) taste, 3) smell, 4) touch, 5) hearing, 6) unknown/ experiential, 7) temperature ${ }^{3}$. Tag number 6 was specially challenging, as some instances showed clear sensory evaluation, but it was unspecified or referred to the experiential domain of aesthetic experience. Sometimes, instances did not evaluate in sensory terms.

2. The cognitive: several considerations took place in the evaluation of aesthetic objects or people. These tags were created $a d$ hoc after individual occurrences surfaced and then were finally edited, grouped or split in a second revision. They are the following: 1) morality, 2) religiousness, 3) holiness, 4) cleanness, 5) royalty, 6) value, 7) goodness (generally speaking and unspecified) and 8) familiarity. Tentatively, an additional tag 9) novelty was included, but it proved not to be lexically rendered in any excerpt. Some instances were specific enough to facilitate a straight-forward categorisation, but other instances were not so detailed and were grouped under 2.7) goodness.

3 Even if temperature could be considered as part of the sense of touch, in this study they are tagged separately in order to test whether temperature plays a specific role in aesthetic experience or not. 
MIXING PLEASURE AND BEAUTY: POSITIVE AESTHETIC EXPERIENCE IN OLD ENGLISH POETRY

3. The behavioural: formerly considered by most researchers as part of the cognitive. I followed the practice of Gladkova and Romero-Trillo (2014), who include the behavioural dimension of aesthetic judgment as a separate domain of action in the semantic explications of Present-Day English beautiful. The tags contained in this division are the following: 1) acting according to God's wishes and law, 2) acting according to human laws, 3) peaceful behaviour, 4) actions resulting in prosperity, 5) pleasurable behaviour, 6) acts of power, 7) eloquent speech acts, 8) favourable circumstances, 9) elegant displays. In this context, tag number 3.5 'pleasurable behaviour' understands the experience of pleasure in the behavioural dimension, in order to dissociate the emotion of pleasure from cognition and sensory experience, which remains, to a certain degree, unprocessed cognitively.

Furthermore, these fragments were assessed in cognitive and sensory terms. One of the most discussed ideas in aesthetic emotion theories is the extent to which aesthetic experience is more sensory or cognitive, or to what degree they are combined. The last tag indicates whether the fragments are exclusively sensory or cognitive, or whether there is a combination of the cognitive and the sensory in the aesthetic judgment. Sorting the occurrences using these different tags will make it possible to create tables of cooccurrence for these categories and also for the accompanying lexis that ultimately provides information about what a lexical item means and how it was once conceptualised.

Finally, this study draws from the methodology used in similar studies in the field of OE. These studies include the works of Díaz-Vera (2011, 2014, and particularly 2015), Díaz-Vera and Manrique-Antón (2015), or Gevaert (2007), who reconstruct the cultural model for a given emotion in OE departing from linguistic data to arrive at cultural and social conclusions.

\section{THE LEXICAL FIELD OF POSITIVE AESTHETIC EMOTIONS}

There is an abundant variety of poetic lexis to express positive aesthetic emotions in OE. They represent the Anglo-Saxon poet's wordboard to designate beautiful and pleasant entities, objects and circumstances. This is not to say that these are the only possible terms that once existed in OE: they are the ones that were written down and that have been passed onto us. Most of these terms, much like the rest of the OE poetic vocabulary ${ }^{4}$, did not survive into Present-Day English, having been replaced over the centuries by Latin and French words.

4 For a more detailed account of the survival of OE poetic lexis, see Juzi (1939). 
The lexical items have been arranged and distributed in thematic groups to facilitate a more straight-forward analysis and exposition of the results ${ }^{5}$. The information provided in the following subsections is the result of a fine-grained analysis of the concordance, and, therefore, the groups proposed are representative of the Anglo-Saxon conceptualisation of aesthetic experience. Moreover, and since this study combines quantitative and qualitative methods of analysis, it should be highlighted that aim of this section is to provide a data-driven and qualitative discussion of the concordance, while the next section will assess it in quantitative terms.

\subsection{APPEARANCE}

Traditionally, the first and foremost domain of aesthetic experience is the sensory. The first concept that inevitably comes to mind when discussing beauty is outer appearance. There are 12 lexical items in this group, belonging to 6 different lexemes.

a) OE $c \bar{y} m$-: this lexeme is represented by three OE terms, the adjectives OE $c \bar{y} m e$, OE $c \bar{y} m l i c$ and the adverb OE $c \bar{y} m l i c e$. The DOE defines it as "fine, comely, handsome" (DOE, s.v. cȳme, adj. 1), which is applicable to OE cymlic. An approximate translation of the adverb would be "beautifully". This is one of the few surviving OE aesthetic terms, even if its usage is rather archaic by now. The OED acknowledges the usage of PDE comely as "literary" and defines it as "(especially of a woman) pleasant to look at" (OED, s.v. comely, adj. 1). It refers to the outward appearance of aesthetic objects, used to stress a pleasant and strictly visual appearance, as it can be seen in the following example:

(1) Hierusalem, geara ðu wære swa swa cymlic ceaster getimbred (PPs 121.3)

'in the old days, you, Jerusalem, were built as such a beautiful city'

BTD also reinforces the idea of pleasantness and adds the nuance of convenience, defining OE cymlīc as "comely, convenient, lovely, beautiful, splendid" glossed alongside Latin aptus, commodus, splendidus (BTD, s.v. cymlīc, adj. 1). This lexeme is limited in terms of attestations, with only 3.

5 Due to space limitations, this article features only two thematic groups, the remaining (adornment, cleanness, colour, uniqueness, intricacy and light) will be explored in further publications, using the findings presented in this papers as a theoretical basis.

6 Texts are cited using the DOE's Short Title nomenclature available from their website <https://tapor. library.utoronto.ca/doe/\#listoftexts> (Accessed 11 Nov 2019).

7 The translation proposed for these excerpts is my own. 
b) OE foeg(e)r-: this lexeme comprises the different derivates of one of the most important terms to refer to beauty in OE. It includes the adjective OE faeger 'beautiful', the adverb OE fagere 'beautifully', and the verb OE fagrian 'to become beautiful'. It is one of the most attested lexemes in the concordance, with a grand total of 142 occurrences. In 2019, I conducted a full analysis of the adjectival form (see Minaya 2019), in relation to the connection it exhibited between inner and outer beauty. One of the most remarkable conclusions from this study is that this adjective occurs 10 times more in poetic texts than in prose, justifying thus the choice of poetic texts for this analysis.

OE foeger- evaluates in sensory, cognitive and behavioural terms. The DOE points out that OE foeger is applied to three main senses: sight, smell and hearing.

(2) [englum] singað ful healice hludan stefne, fægre feor ond neah. (ChristA,B,C 385)

'the angels sing highly with loud, beautiful voices, far and near'

(3) Jone wudu weardap wundrum fæeger fugel feprum strong, se is fenix haten (Phoen 85)

'the woods are guarded by a wonderfully beautiful bird with strong feathers called the Phoenix'

However, there is evidence that OE foeger was likewise used in close personal experience. In PPs 108.24, the oils that are used for anointing are referred to as OE fagrum ele 'beautiful* (pleasant) oils'. In this case, OE fager could refer to both smell and touch. The adjoining lexical evidence does not clarify it. However, there is an additional and rather obscure instance in the concordance where $\mathrm{OE}$ foeger evaluates in terms of taste:

(4) Ys sawl min swetes gefylled, swa seo fætte gelynd, fægeres smeoruwes (PPs 62.6)

'my soul is sweetly filled [by God's grace], just as if it were filled with beautiful* (pleasant) grease'

This exemplifies an interesting conceptualization of the Christian state of grace, compared to an everyday sensory phenomenon, like tasting grease. OE foeger also evaluates in moral, cognitive and spiritual terms. This is often the case when the adjective is applied to religious figures, like God, Christ, or the Saints or to actions carried out by them:

(5) Ne ic him mildheortnesse mine wille fægere afyrran (PPs 88.31)

'I will not remove him from my beautiful mercy' 
Sometimes, it is not possible to separate instances in terms of exclusively sensory or cognitive.

However, one of the most recurrent usages of OE fager, which connects with the fourth sense in the DOE "fair, favourable, benign; not disturbed" (DOE, s.v. foeger, adj. 4), is the experiential domain of human existence. OE foeger is frequently used to convey the pleasant and undisturbed state of those who follow God's wishes and the retribution that they will achieve when they arrive to heaven. In El 945, the love of the lord, OE lufan drybtnes, is described as OE pone foegran gefean 'the beautiful* (pleasant) joy'. While this last sense of OE fager was typically connected to weather and sea, it also made reference to "(way of) life, state, condition" and "religious belief" (DOE, s.v. foeger, adj. 4b and 4c). In this sense, the $\mathrm{OE}$ adjective foegere is used with similar meaning, depicting the behavioural dimension of aesthetic experience.

The usage of the OE verb faegrian 'to become beautiful' is more rare, with only one attestation in the concordance and visual evaluation. Semantically, it is similar to the OE verb wlitegian, 'to become/make beautiful' with the exception that OE fogrian is only used as intransitive, while OE wlitegian can be used both as intransitive and as transitive. For instance:

(6) Bearwas blostmum nimað, byrig fægriað, wongas wlitigiað, woruld onetteð (Sea 48)

'the woods catch blossoms, the cities become beautiful, and the fields, too; the world is quickened'

In this fragment from The Seafarer, the OE verb faegrian establishes a contrast between the cold and desolate world of the outlawed seafarer and the aesthetic richness of a world that is quickened by the arrival of spring.

c) OE frēolic and $\mathrm{OE}$ ceðele: it is not entirely unusual to find polysemy in aesthetic terms. Words like OE frēolic and OE ceðele, which in their first senses mean 'noble/royal', are also used in aesthetic contexts as synonymous of beautiful. For OE frēolic, the DOE points out a third sense defined as "of things: excellent, noble, beautiful" (DOE, s.v. frēolic, adj. 3). The same could be said of OE aeðele: while the main sense of the adjective is "noble, famous" (DOE, s.v. ceðele, adj.), the DOE acknowledges an aesthetic dimension to it in sense number 3. See for instance:

(7) Syleð us fremsum god fægere drihten, ponne us eorðe syleð æðele wæstmas (PPs 84.11).

'give us your kind goods, beautiful lord, when the earth gives its noble* (beautiful) fruits' 
This excerpt is particularly interesting because it features the usage of $\mathrm{OE}$ aeðele in an aesthetic context (there is nothing noble about an apple), but it should be taken with extrema care; as the DOE (s.v. aeðele, adj. 3.b) points out OE ceðele, and other aesthetic lexis like OE foeger, in the Paris Psalter is "often of little meaning, but useful for vocalic alliteration". In the following example, the aesthetic evaluation is more evident:

(8) mon secan sceal be sæwaroðe and be ea ofrum æpele gimmas, hwite and reade and hiwa gehwæs (Met 19.20)

'men shall seek around the shore and the running water the noble* (beautiful) gems, white, red and of every other colour'

In order to avoid this semantic ambiguity, I have followed the practice of categorizing both of these terms in the thematic group of "appearance," but only when it was clear from the individual analyses of the attestations of these words that there was a degree of aesthetic judgment. These two terms reinforce the idea that what was royal was innately conceptualised as beautiful, and, by extension, when this term was aesthetically applied to non-royal people or entities, it alluded to sensory qualities of extreme beauty, characteristic of those who were royal:

(9) ac him brego engla of lice ateah liodende ban, wer unwundod, of pam worhte god freolice fæmnan (GenA,B 178)

'the Lord of Angels drew forth that burgeoning bone from his body, the man unwounded, and from there God created a beautiful woman'

The nobility of these entities is not only related to their position as kings or queens, but also as connected with ideas of divinity and holiness. While this is a clear combination of a visual and spiritual evaluation, there are other possible combinations.

The DOE points out that the OE adjective aeðele can be used in aesthetic contexts as synonymous of sweet: "æðele stenc 'sweet smell' used figuratively; also the odour of sanctity and of the resurrected Christ" (DOE, s.v. ceðele, adj. 3.d.). This event is further developed in Phoen 583, where the Phoenix and Christ are said to depart together with a OE eadwelum apelum stencum 'blessed noble* (sweet) smell'. One characteristic of Anglo-Saxon religious texts is that they often depart from oculocentrism, and depict spiritual phenomena involving unusual senses, like smell.

d) OE hìw represents a similar phenomenon. While its main sense is "form, figure" (DOE, s.v. hiw , n. 1), its usage as a positive aesthetic emotion marker is 
acknowledged in sense number 2: "2.b. specifically: beautiful appearance: beauty" (DOE, s.v. hiw, n. 2.b). Moreover, the DOE also contemplates the spiritual and moral extension of this physical beauty in a subdivision: "in spiritual or figurative sense" (DOE, s.v. hīw, n. 2.b). This polysemy becomes increasingly challenging in some contexts, where it is unclear whether OE $h \bar{i} w$ refers to shape or beauty. For instance, in Jul 244, the demon who visits Juliana in jail and tries to trick her OE hoefde engles biw 'has an angel's shape/beauty'. The case of angels is not as misleading as it could be elsewhere, as they are one of the entities that are traditionally depicted as always beautiful. It could be said, therefore, that in this example, as in many others in the database, OE hìw refers to both beauty and shape.

e) Similar to OE $h \bar{i} w$ is the case of OE wlite. According to BTD, it can either mean "aspect, countenance" (BTD, s.v. wlite, n. I) or "beautiful appearance" (BTD, s.v. wlite, n. II). In some cases, the context is clear enough to provide a straight-forward reading of OE wlite as 'beautiful', but in other cases OE wlite could refer both to appearance and to beauty, like its usage in the OE poem Daniel:

(10) Ne mihte peah heora wlite gewemman owiht wylm pæs wæfran liges, pa hie se waldend nerede.

'not one bit was their beauty/appearance stained by the boiling of the quivering flames when the Lord saved them'

In this passage, God has sent an angel to save the three youths from the oven in which they were going to burn. The usage of OE wlite alongside OE gewemman 'to stain' not only introduces the idea of stain as ugliness, but it also connects beauty to cleanness. In other cases, for instance in the poem Christ and Satan, we find the collocation hafdon wlite (Sat 149) 'to have a beautiful appearance'. In this case, having "appearance" would not make sense.

f) Alongside OE fager, OE wlitig is one of the main lexical indicators of beauty. Etymologically, it comes from the Proto-Indo European root *uel- 'to see' (Pokorny, 1959: 3290). In the Germanic branch, this sense prevailed (for instance, OE wlitan 'to see') but it also evolved to mean appearance, and by extension positive appearance, that is, beauty (for instance, Gothic wlits 'shape', but also Gothic wulpus 'splendor'). BTD indicates two domains of evaluation. First, "of beauty that appeals to the senses" (BTD, s.v. wlitig, adj. I). It includes both celestial and earthly beauty, and contemplates visual, aural and olfactory sensory treatment. In fact, sometimes OE wlitig groups both the visual, the olfactory and the experiential (see the usage of OE wynn 'pleasure'): 
MIXING PLEASURE AND BEAUTY: POSITIVE AESTHETIC EXPERIENCE IN OLD ENGLISH POETRY

(11) Wlitig is se wong eall, wynnum geblissad mid pam fæegrestum foldan stencum (Phoen 7)

'all the land is beautiful, rejoicing with the pleasure of the most beautiful perfumes of the earth'

When the poet refers to the beauty of the OE wong 'land, plain' it explicitly alludes to smell, but it also has a visual implication. Moreover, God's voice (OE stefn) is described in Jul 282, as OE wlitig 'beautiful/pleasant'. Second, OE wlitig refers to "beauty that appeals to the mind" (BTD, s.v. wlitig, adj. II). In this case, the context is almost always religious, to the point that OE wlitig becomes nominalized in describing those that are saved by God in Doomsday:

(12) Wile ponne gesceadan wlitige and unclæne on twa healfe, tile and yfle (Sat 608)

then [on Doomsday] He will separate the beautiful and the unclean on two halves, the good and the bad'

This moral beauty, like in many other instances, refers to the morality and behaviour of those who act according to God's wishes. The contrary implies the uncleanness of being stained with sin.

\subsection{PLEASANT PERSONAL EXPERIENCE}

Rather than focusing on pleasure, which qualifies as a fairly broad emotion, this subsection focuses on lexical items describing personal pleasant experience as a result of the aesthetic emotion episode. People, objects and situations in this category are defined as pleasant, lovely or delightful because of their cognitive or sensory characteristics. This group contains 5 different lexemes, with 7 different lexical items.

a) OE leōflic and OE luflic are two terms that have also survived into PresentDay English lovely. They translate as "lovely, beautiful, delightful, pleasant, lovable, dear" (BTD, s.v. leōflic , adj.). In his discussion on the nature of aesthetic emotion, Thornton (1940: 199) pointed out that there was a fundamental element of affection in aesthetic experience. This is reflected in some of the terms in this thematic group, which connect affection and mild aesthetic experience. In the aesthetic emotion theory proposed by Juslin (2013: 248), when the sensory data is cognitively processed and is just above the aesthetic threshold, the aesthetic experience that is triggered is not that of the experience of beauty, but that of simply "liking" an object, or finding it "lovely". These terms refer to this mild aesthetic experience, somewhere below beauty and above liking. The emphasis in these cases is not on the object's qualities, but rather on the feelings of pleasure it provokes on the subject: 
(13) pone wlitigan wong ond wuldres setl, leoflic on laste (Phoen 437) 'the beautiful plain and settlement of glory, lovely on their steps'

It is clear how OE leofflic refers to the aesthetic response on the part of the subject, rather than to the qualities of the aesthetic object. However, this term is not very frequent in the concordance, with only 4 attestations.

b) There are other three terms that denote pleasant personal experience but that are likewise not very frequently attested. First, there is OE swinsian "to make a (pleasing) sound, make melody or music" (BTD, s.v. swinsian, vb.). It is the only lexeme so far where the idea of close personal pleasant experience is lexically encoded in the root. According to Pokorny (1959: 3016) it is derived from the Proto-Indo-European root *suen-, meaning "to sound". This connection with pleasant sounds is not found in other Germanic languages. Furthermore, it reinforces the important role of music in Anglo-Saxon society, inherently thought of as pleasant. One of the two poetry attestations is found in Phoen 124, where the bird is said to OE swinsað ond singeð 'make a pleasant sound and sing'.

Second, we find OE wilsele, also with one attestation. It translates as "pleasant hall" (BTD, s.v. wilsele, n.), and it is a compound of two OE terms: OE wil 'will', but also 'pleasant or desirable thing' (BTD, s.v. wilsele, n. 2).

(14) Wyrta wearmiað, willsele stymeð swetum swæccum

'[when the sun comes up] the plants are warmed, and the pleasant hall emits the sweetest smells'

The idea of 'hall' is metaphorical in this excerpt, as this fragment refers to the Phoenix's nest, reimagined as hall. It is expressed as pleasant because the herbs it is made of are warmed at sunrise and they emit sweet smells. Yet, the role of alliteration in this excerpt cannot be overlooked. Some of the figurative usages of aesthetic emotion terminology can be explained by the alliterative constraints of the sentence under analysis.

Also in the OE Phoenix, there is a third term which is only attested once in poetry: OE gefeālīc 'pleasant, joyous, delightful' (BTD, s.v. gefeālīc, adj.). The sign of the Phoenix is described as OE fager ond gefealic fugles tacen (Phoen 508) 'beautiful and pleasant, the bird's token'. In this excerpt, both types of aesthetic experience are lexically rendered: the subjective (related to the subject's feelings) and the objective (related to the object's qualities).

c) Lastly, one of the most fertile lexemes in the category of personal pleasant experience is OE wyn-, containing the nominal OE wyn 'pleasure, delight' and 
the adjectives OE wynsum 'pleasant' and OE wynlīc 'delightful, pleasing'. There is no difference between the two adjectival derivatives in terms of meaning; in terms of usage, OE wynsum is more frequently attested. BTD points out two meanings for OE wynsum, which are similarly applicable to OE wynlīc: "winsome, agreeable, pleasant" (BTD, s.v. wynsum, adj. I) and acknowledges the three typical domains of aesthetic evaluation: the senses, the mind and people's conduct. The other sense indicated is as a synonym of joyous (BTD, s.v. wysum, adj. II). This term is also frequently used to convey the religious experience of the state of grace of the arrival of the soul to heaven, as Blake (1964: 30) points out in relation to the usage of this lexeme in The Phoenix: "the difficulty the poet came up against was how to express in positive terms what heaven means to the soul, a difficulty he tried to solve by a heavy reliance on adjectives expressive of joy, majesty, light and bliss".

(15) pæt wæs swete stenc, wlitig ond wynsum geond woruld ealle (Pan 64)

'it was a sweet smell [that of Christ resurrected], beautiful* and pleasant through the world'

There are several reasons for the combination of OE wlitig and OE wysum. On the one hand, they alliterate and introduce ideas which are similar. On the other hand, one term makes reference to the seemingly objective qualities of the smell of Christ, while the other alludes to the effect that this smell has on the subject.

Lexis referring to appearance is often found in combination with personal pleasant experience, creating poetic passages of hyperbolic depictions of beauty:

(16) wordum spræcon ymb pæs wifes wlite wlonce monige [...]. Hie pæt cuð dydon heora folcfrean and fægerro lyt for æðelinge idese sunnon, ac hie Sarran swiðor micle, wynsumne wlite wordum heredon, oðpæt he lædan heht leoflic wif to his selfes sel (GenA,B 1847)

'many words were spoken about that woman's [Sarah's] beauty [...]. They explained to their people, many words were heard about the woman's pleasant beauty, and said that there have been very few women as beautiful as she was standing before the king until the moment that he ordered the pleasant/lovely woman to be brought to his own hall'

This excerpt features a great array of aesthetic lexis: OE wlite 'appearance/ beauty', OE faeger 'beautiful', OE wynsum 'pleasant' (to be discussed in this section), and OE leoflic 'lovely'. However, the first two refer to the beauty of Abraham's wife as a perceptual quality connected to her, while the last two refer to the physical effect the aesthetic emotion episode has on the beholder. 
More specifically, this combination of appearance and pleasant experience lexis displays an attempt to express disembodied concepts. Spiritual experiences like seeing Christ or Jesus, much like the arrival of the soul to heaven discussed before, are difficult to conceptualise. For instance:

(17) He bið pam godum glædmod on gesihpe, wlitig, wynsumlic, weorude pam halgan, on gefean fæger, freond ond leoftæl, lufsum ond lipe leofum monnum to sceawianne pone scynan wlite (ChristA,B,C 918)

'he is good to those who are visibly glad, beautiful and pleasant to his people, beautiful on his rejoice, friend and dear, kind and gentle for the men who behold his shining beauty'

Every aesthetic term in this description places the focus on the sensory, the cognitive and the experiential. The Theory of Embodiment (see Rosch, Thompson and Varela 1991) stresses the impossibility of having disembodied cognition: all human experiences are filtered through the lenses of physicality. In consequence, Anglo-Saxon poets resorted to lexis that was traditionally associated with feelings of positive bodily experience as well as lexis used to carry out visual and cognitive judgments to create poetic descriptions of supernatural experience that could be easily understood by Anglo-Saxon audiences on the basis of their connection with their everyday experience. By constructing aesthetic experience in these terms, spiritual ideas become not only understandable for a broader audience, but at the same time they are enjoyed aesthetically.

\section{DISCUSSION}

The in-depth analyses of these 23 lexical items, distributed in 313 different fragments with 411 tokens, sheds some light about the intentional creation of beauty on the part of the Anglo-Saxon poet and about the role that these terms had in conceptual, semantic and stylistic terms. In this section, I will quantitatively asses the pertinent sections of the concordance as a whole in order to statistically contrast the remarks made in the previous section with the data extracted from the different tags. Table 1 displays the number of attestations for the different aesthetic lexis analysed. Among them, OE oeðele, foeger and wlitig stand out as the main poetic aesthetic descriptors for cognitive, behavioural and sensory beauty, while OE wynsum is noted as the most frequently used term to refer to personal pleasant experience. These terms are part of the core poetic vocabulary in $\mathrm{OE}$ and they carry semantic associations that make them more suitable in particular contexts. 
Table 1. Number of attestations.

\begin{tabular}{|c|c|c|c|}
\hline Term & Theme & Translation & Attestations \\
\hline aeðele & APPEARANCE & $\begin{array}{c}\text { noble, eminent, } \\
\text { beautiful }\end{array}$ & 89 \\
\hline foeger & APPEARANCE & beautiful & 75 \\
\hline foegere & APPEARANCE & beautifully & 66 \\
\hline wlitig & APPEARANCE & beautiful & 49 \\
\hline wlite & APPEARANCE & beauty, appearance & 37 \\
\hline wynsum & Pleasant EXP. & pleasant & 33 \\
\hline freōlīc & APPEARANCE & comely & 19 \\
\hline wynlic & Pleasant EXP. & delightful, pleasing & 7 \\
\hline wyn & Pleasant EXP. & pleasure, delight & 6 \\
\hline wlitescine & ApPeARANCE & of brilliant beauty & 6 \\
\hline gewlitegian & ApPeARANCE & to make beautiful & 6 \\
\hline leōflìc & Pleasant eXP. & lovely, beautiful & 4 \\
\hline$b \bar{i} w$ & APPEARANCE & colour, appearance & 4 \\
\hline cyme / cymlic & APPEARANCE & lovely, beautiful & 2 \\
\hline swinsian & Pleasant exp. & $\begin{array}{c}\text { to make a pleasant } \\
\text { sound }\end{array}$ & 2 \\
\hline wilsele & Pleasant EXP. & pleasant hall & 1 \\
\hline wrōest & ApPeARANCE & elegant & 1 \\
\hline gefeālīc & Pleasant EXP. & pleasant, joyous & 1 \\
\hline foegrian & APPEARANCE & to become beautiful & 1 \\
\hline cymlice & APPEARANCE & beautifully & 1 \\
\hline ans $\bar{y} n$ & APPEARANCE & face, countenance & 1 \\
\hline \multicolumn{3}{|c|}{ Total tokens analysed: } & 411 \\
\hline
\end{tabular}

Other terms like OE leōflic or those derived from OE cyme are not so frequently attested. The fact that their Present-Day English derivates are part of the everyday aesthetic vocabulary may indicate that they were too in OE times. However, these assumptions have to be empirically proved in further research, for which I will engage in an analysis of the complete prose and poetry corpora. 
As for the categorization of these occurrences in the categories specified in section 3 (Table 2), it becomes clear that there are two main domains of sensory evaluation, the visual and the experiential. The rest of the senses are also present in the corpus, but with a notably lower frequency. Touch, including temperature, is less frequently treated in the poetic corpus. The tags related to cognitive aesthetic evaluation reflect the religious nature of the poetic material: most of the cognitive aesthetic judgments are carried out on the basis of holiness or religiousness. The value of the aesthetic object is also an important part in its perception as object of beauty or pleasure. Familiarity, a key appraisal of aesthetic experience, while present on the aesthetic emotion episode, is not very frequently lexically rendered. As for the behavioural, a great proportion of the instances where a person's conduct is deemed beautiful or pleasant is connected with their adherence to God's wishes. Other fairly often attested behavioural evaluations include a person's eloquence or displays of power as pleasant or beautiful, or the evaluation of a given period as favourable.

Table 2. Categorisation.

\begin{tabular}{|l|c|l|c|l|c|}
\hline \multicolumn{2}{|c|}{ Sensory } & \multicolumn{2}{c|}{ Cognitive } & \multicolumn{2}{c|}{ Behavioural } \\
\hline 1. Sight & $60 \%$ & Morality & $8.96 \%$ & God's wishes & $58.90 \%$ \\
\hline 2. Taste & $1.66 \%$ & Religiousness & $18.62 \%$ & Human law & $3.42 \%$ \\
\hline 3. Smell & $8.01 \%$ & Holiness & $46.20 \%$ & Peaceful behaviour & $4.10 \%$ \\
\hline 4. Touch & $0.27 \%$ & Cleanness & $6.89 \%$ & Prosperity & $6.16 \%$ \\
\hline 5. Hearing & $6.63 \%$ & Royalty & $3.44 \%$ & Pleasurable behav. & $3.42 \%$ \\
\hline 6. Experiential & $22.10 \%$ & Value & $10.34 \%$ & Power & $6.85 \%$ \\
\hline 7. Temperature & $0.83 \%$ & Goodness & $4.13 \%$ & Eloquence & $7.53 \%$ \\
\hline & & Familiarity & $1.37 \%$ & Favourable & $6.85 \%$ \\
\hline & & & & Elegance & $2.74 \%$ \\
\hline
\end{tabular}

One of the questions I aimed to answer was whether the construction of beauty in the poetic corpus was carried out in exclusively sensory or cognitive terms, or if the combination of cognitive and sensory stimuli was more frequent. The results are unclear: the combination of sensory and cognitive aesthetic judgments is as frequent as the individual aesthetic evaluation. Therefore, there is not a clear preference for one type of aesthetic judgment. 
Table 3. Evaluation.

\begin{tabular}{|l|c|}
\hline \multicolumn{2}{|c|}{ Combination } \\
\hline Yes & $49,84 \%$ \\
\hline No & $48,24 \%$ \\
\hline Undetermined & $1,91 \%$ \\
\hline
\end{tabular}

\section{CONCLUDING REMARKS}

This thematic separation of some of the aesthetic lexis in this study highlights the dual dimension of Old English depictions of beauty, basing on two different responses to aesthetic emotion. On the one hand, lexical items grouped in the thematic group concerning appearance were more used in evaluations focusing on how the aesthetic object is (both cognitively and in sensory terms). In this sense, this construction of beauty aims at being more objective. On the other hand, terms in the pleasant personal experience group place the emphasis, not on the qualities of the subject, but on how it makes the subject feel. As such, they are more subjective.

Lexis concerning appearance does not only refer to sensory aesthetic experience; they are multi-purpose words. As I already showed in Minaya (2019), terms like OE foeger, referring to outer beauty, also evaluated inner beauty and people's behaviour. Other terms like OE cyme only evaluate in sensory terms. Nevertheless, the tendency for the lexical items in the appearance thematic group evaluate in all the different areas of human experience. The sensory semantic meaning is made extensive to the cognitive and the behavioural, and sometimes it becomes difficult to determine whether a lexical item evaluates in one or the other sense. The same phenomenon occurs as far as polysemy is concerned: some lexical items that do not have a main aesthetic meaning are taken to mean 'beautiful', showing a connection between a given word and the idea of beauty. This is also the case of words meaning 'appearance', which are taken to mean 'beauty' in particular context. Furthermore, future research is to determine whether this is also the case of other lexical domains.

While there is a marked predominance of the visual, OE poetry also took pleasure in aesthetic representations involving other senses. Some of them are more unusual, like aesthetic experiences involving taste, whereas others involving hearing and smell are configured around experiences of a religious nature that give the event an everyday flavour. This is one of the most notable poetic displays in the instances analysed, and where the importance of the lexis 
for personal pleasant experience is reinforced. By mixing terminology typically associated with everyday visual, olfactory, aural and experiential phenomena, the poet tells the audience not only how the aesthetic object is, but also how they should feel about it. In other words, by mixing beauty and pleasure, the Anglo-Saxon poet evokes embodied feelings and emotions on the subject and then contextualises them in a disembodied context, one that is not so easily understood due to its abstract nature. Skilfully describing religious experiences in embodied terms as pleasant or appealing gives the poet the opportunity of causing the subject to envision and physically experience abstract and spiritual events, which accompanied by poetic descriptions of light and colour, and precious and wondrous objects and people, engage the subject in an aesthetic emotion episode where the invisible is lived through previously-lived phenomena of superb beauty and aesthetic pleasure.

\section{REFERENCES}

Atkins, B. T. S. 1987. "Semantic ID tags: corpus evidence for dictionary senses". Proceedings of the Third Annual Conference of the UW Centre for the New Oxford English Dictionary: 17-36.

Berlyne, D. E., ed. 1974. Studies in the new experimental aesthetics: Steps towards an objective psychology of aesthetic appreciation. Oxford: Hemisphere.

Bitterli, D. 2016. "Strange Perceptions: Sensory Experience in the Old English 'Marvels of the East". The Five Senses in Medieval and Early Modern England. Eds. A. Kern-Stähler, B. Busse and W. de Boer. Leiden: Brill. 137-162.

Blake, N. F. 1964. The Phoenix. Manchester: Manchester University Press.

Bosanquet, B. 1894. "On the Nature of Æsthetic Emotion”. Mind 3 (10): 153-166.

Bosworth, J. and T. N. Toller with S. Crist, O. Tichy, M. Hejná, H. Filipová and L. Gillova. 2013. Bosworth-Toller Anglo-Saxon Dictionary: Faculty of Arts, Charles University in Prague. <http://bosworth.ff.cuni.cz>.

Cameron, A., Crandell Amos, A. and A. di Paolo Healey et al. (eds.). 2018. Dictionary of Old English: A to I online. Toronto: Dictionary of Old English Project. <https://tapor.library.utoronto.ca/doe/>. (Accessed July 2019).

Cupchik, G. C. 2016. The Aesthetic of Emotion: Up the Down Staircase of the MindBody. Cambridge: Cambridge University Press.

Damasio, A. R. 1999. The feeling of what happens: Body and emotion in the making of consciousness. New York: Harcourt.

Díaz-Vera, J. E. 2011. "Reconstructing the Old English cultural model for fear". Atlantis. Journal of the Spanish Association of Anglo-American Studies 33 (1): 85-103. 
MIXING PLEASURE AND BEAUTY: POSITIVE AESTHETIC EXPERIENCE IN OLD ENGLISH POETRY

Díaz-Vera, J. E. 2014. "From cognitive linguistics to historical sociolinguistics: The evolution of Old English expressions of shame and guilt". Cognitive Linguistic Studies 1 (1): 55-83.

Díaz-Vera, J. E. 2015. "Exploring the relationships between emotions, language and space: Construals of AWE in medieval English language and pilgrimage experience". Studia Neophilologica 88: 165-189.

Díaz-Vera, J. E. and T. Manrique-Antón. 2015. "Better shamed before one than shamed before all': Shaping shame in Old English and Old Norse texts". Metaphor and Metonymy across Time and Cultures. Ed. J. E. Díaz-Vera. Berlin: Walter de Gruyer. 225-264.

diPaolo Healey, A., with J. Price Wilkin and X. Xiang (Compilers). 2009. Dictionary of Old English Web Corpus. Toronto: Dictionary of Old English Project.

Eco, U. 2004. On Beauty: A History of a Western Ideal. London: Secker \& Warburg. Trans. Alastair McEwen.

Frijda, N. H. 1988. "The laws of emotion". American Psychologist 43 (5): 349358.

Frijda, N. H., Kuipers, P. and E. ter Schure. 1989. "Relations Among Emotion, Appraisal, and Emotional Action Readiness". Journal of Personality and Social Psychology 57 (2): 212-228.

Gevaert, C. 2007. The history of ANGER: The lexical field of ANGER from Old English to Early Modern English. Unpublished Ph.D. thesis. Katholieke Universiteit Leuven: Leuven. <https://core.ac.uk/download/pdf/34435415.pdf>. (Accessed 28 Aug. 19)

Gladkova, A. and J. Romero-Trillo. 2014. "Ain't it beautiful? The conceptualization of beauty from an ethnopragmatic perspective". Journal of Pragmatics 60: 140-159.

Gries, S. T. 2010. "Behavioral Profiles: A fine-grained and quantitative approach in corpus-based lexical semantics". The Mental Lexicon 5 (3): 323-346.

Gries, S. T. and N. Otani. 2010. "Behavioral Profiles: A corpus-based perspective on synonymy and antonymy”. ICAME Journal 34: 121-150.

Hagman, G. 2005. Aesthetic Experience: Beauty, Creativity, and the Search for the Ideal. Amsterdam: Editions Rodopi.

Hill, J. M., ed. 2010. On the Aesthetics of Beowulf and Other Old English Poems. Toronto: University of Toronto Press.

Ibarretxe-Antuñano, I. 2013. "The relationship between conceptual metaphor and culture". Intercultural Pragmatics 10 (2): 315-339. 
Izard, C. E. 1977. Human emotions. New York: Plenum Press.

Juslin, P. N. 2013. "From everyday emotions to aesthetic emotions: Toward a unified theory of musical emotions". Physics of Life Reviews 10 (3): 235-266.

Juzi, G. 1939. Die Ausdrücke des Schönen in der ae. Dichtung: Untersuchung über ein sprachliches Feld. Zurich: Aschmann \& Scheller.

Kim, S. M. and A. S. Mittman. 2010. "Ungefroegelicu deor: Truth and the Wonders of the East”. Different Visions. A Journal of New Perspectives on Medieval Art 2: 1-22.

Kytö, M. 1996. Manual to the Diachronic Part of The Helsinki Corpus of English Texts: Coding Conventions and List of Source Texts. Helsinki: Helsinki University Printing House.

Lazarus, R. S. 1991. "Progress on a cognitive-motivational-relational theory of emotion". American Psychologist 46 (8): 819-834.

Lockett, L. 2011. Anglo-Saxon Psychologies in the Vernacular and Latin Tradition. Toronto: University of Toronto Press.

Marković, S. 2012. "Components of aesthetic experience: aesthetic fascination, aesthetic appraisal, and aesthetic emotion". i-Perception 3: 1-17.

Marwick, A. 2004. It: A History of Human Beauty. London and New York: Hambeldon and London.

Menninghaus, W., Wagner, V., Wassiliwizky, E., Schindler, I., Hanich, J., Jacobsen, T. and S. Koelsch. 2019. "What Are Aesthetic Emotions". Psychological Review 126 (2): 171-195.

Miller, G. A. and W. G. Charles. 1991. "Contextual correlates of semantic similarity". Language and Cognitive Processes 6 (1): 1-28.

Minaya, F. J. 2019. "As beautiful inside, as it is outside: On the connection between beauty and morality in the Old English corpus". Complutense Journal of English Studies 27: 205-221.

Möhlig-Falke, R. 2016. "Using the 'Dictionary of Old English Corpus' for linguistic analyses: a basic classification of the textual sources". Neuphilologische Mitteilungen 15 (1): 395-420.

Munteanu, D. L. 2009. "Qualis tandem misericordia in rebus fictis?' Aesthetic and ordinary emotion”. Helios 36 (2): 117-147.

Ramey, P. 2017. "The Riddle of Beauty: The Aesthetics of Wrætlic in Old English Verse". Modern Philology 113 (3): 457-481.

Rissanen, M., Kytö, M., Kahlas-Tarkka, L., Kilpiö, M., Nevanlinna, S., Taavitsainen, I., Nevalainen, T. and H. Raumolin-Brunberg (Compilers). 1991. The Helsinki Corpus of English Texts. Helsinki: Department of Modern Languages, University of Helsinki. 
Roberts, J. and C. Kay, with L. Grundy. 2017. A Thesaurus of Old English: University of Glasgow. <http://oldenglishthesaurus.arts.gla.ac.uk/>.

Rosch, E., Thompson, E. and F. Vaerla. 1991. The embodied mind: cognitive science and human experience. Cambridge: MIT Press.

Roseman, I. J. and C. A. Smith. 2001. "Appraisal theory: Overview, Assumptions, Varieties, Controversies". Appraisal Processes in Emotion: Theory, Methods, Research. Eds. K. R. Scherer, A. Schorr and T. Johnstone. New York: Oxford University Press. 3-19.

Scherer, K. R. 1982. "Emotion as a Process: Function, Origin and Regulation". Social Science Information 21: 550-570.

Scherer, K. R. 2005. "What are emotions? And how can they be measured". Social Science Information 44 (4): 695-729.

Shibles, W. 1995. Emotion in Aesthetics. Dordrecht: Kluwer Academic Publishers.

Taylor, A., Warner, A., Pintzuk, S. and F. Beths (Compilers). 2003. The York-TorontoHelsinki Parsed Corpus of Old English Prose and Poetry. York: Department of Language and Linguistic Science, University of York.

Thornton, J. W. 1940. "Aesthetic Emotion". Philosophy and Phenomenological Research 1 (2): 199-207.

Tyler, E. M. 2006. Old English Poetics: The Aesthetics of the Familiar in Anglo-Saxon England. York: York Medieval Press.

Trilling, R. R. 2009. The Aesthetics of Nostalgia: Historical Representations in Old English Verse. Toronto: University of Toronto Press.

Williamson, C. and T. Shippey. 2017. The Complete Old English Poems. Pennsylvania, Phi: University of Pennsylvania Press. 